\title{
Methods Applied in the Prediction of Brittle Failure in Tunnels and Underground Caverns
}

Krishna Kanta Panthi

\begin{abstract}
Tunnels and underground caverns located at greater depth (high rock cover or overburden) are subjected to high in-situ stress environment. Those rock mass that are relatively unjointed and massive are exposed to the brittle failure, which is famously known as rock spalling/ rock bursting phenomenon. Establishing state of the stress and evaluating stress-induced instability in tunnels passing through such rock mass at relatively greater depth is therefore a challenge. The aim of this manuscript is to describes existing brittle failure (rock burst) prediction methods that are being practiced worldwide and propose necessary editions so that quality of assessment is enhanced. The methods described are very practical and the author is confident that professional engineers will use them to evaluate and predict potential rock burst/ rock spalling scenario in the tunnels during planning, design and construction phases. Each method of prediction is explained, applicability extent is highlighted and comparisons between the methods are made.
\end{abstract}

Keywords: Tunnel and underground caverns, in-situ stress environment, rock mass, brittle failure

\section{Introduction}

B lock failure is a common stability challenge for the Bunderground openings excavated near the surface since at near surface in-situ stress (both horizontal and vertical) magnitude are low and the near surface rock mass is influenced by weathering and fracturing. In contrast, underground openings situated at greater depths are exposed to high in-situ stress magnitudes and therefore the major area of stability challenge is associated to stress induced instability. The type and severity of this type of instability depends on the rock type, the mineralogical composition, strength and quality of the rock mass, the geometry of an underground opening and the in-situ stress state. Principally, the stress-induced failure in the periphery of tunnel occurs only when the maximum tangential stress exceeds the rock mass strength. However, the process of failure is of complex and, therefore, of interest to learn about the failure mechanism and instabilities associated to the insitu stress condition.

For a rock engineer involved in the design, construction and operation of underground openings (tunnels and caverns for both civil and mining purpose) located at greater depths, the understanding about failure mechanism is very crucial issue. The three key engineering geological factors directly influencing the stability of tunnels or underground caverns are rock mechanical properties, in-situ stress conditions and groundwater inflow through fractures and weakness/ fault zones (Panthi, 2012). Tunnels and underground caverns passing or located beneath deep rock cover (overburden) are subject to instabilities caused by induced rock stresses. In relatively unjointed and massive strata, if the rock mass strength is less than the induced stresses, the instability is mainly associated to the rock spalling or rock bursting (Panthi, 2017). On the other hand, if the rock mass is weak, schistose, sheared, deformed and thinly foliated/ bedded, squeezing is the most likely scenario (Panthi, 2006).
The main aim of this manuscript is to explain about the brittle failure mechanism in the rock material, briefly discuss on the influence of mineralogical composition on the failure mechanism and to present four most widely used brittle failure (rock spalling/ rock burst) prediction methods in the world. These four methods represent either empirical or semi-analytical approaches and are classified by Panthi (2017)as;1) Norwegian Rule of Thumb (Selmer-Olsen, 1965), 2) Stress Problem Classification - part of Q-system (Barton et al. 1974), 3), Uniaxial Compressive Strength and Tensile Strength Approach (Diederichs, 2007) and 4), Maximum Tangential Stress and Crack Initiation Strength Approach (Martin and Christiansson, 2009). Finally, discussions are also made on the limitations and extent of their applicability and improvements are suggested to improve the applicability of the fourth method, which can be used through engineering decision-making process.

\section{Norwegian Rule of Thumb}

Most of the tunnels built in Norway are for hydropower, road and railways. These tunnels are mostly located in the countryside and pass through steep valley-side slopes. Many of these tunnels experienced rock spalling/ rock burst problems while tunneling through hard and brittle rocks mass. In this respect, the knowledge associated to brittle failure in tunnels is not new in Norway (Panthi, 2017). Already in 1965, Professor Rolf Selmer Olsen of Norwegian Institute of Technology (NTH) studied over 60 tunnels passing parallel with valley-side slope where rock burs and rock spalling were experienced during tunnel excavation (Olsen, 1965). Most of the studied tunnels were passing through the topography where vertical rock cover over these tunnels was relatively small in comparison to the vertical height between the tunnel and top of the valley-side slope; the plateau. More importantly, most of these tunnels had relatively short distance (mostly not exceeding $300 \mathrm{~m}$ ) from the surface (Figure 1-right). 

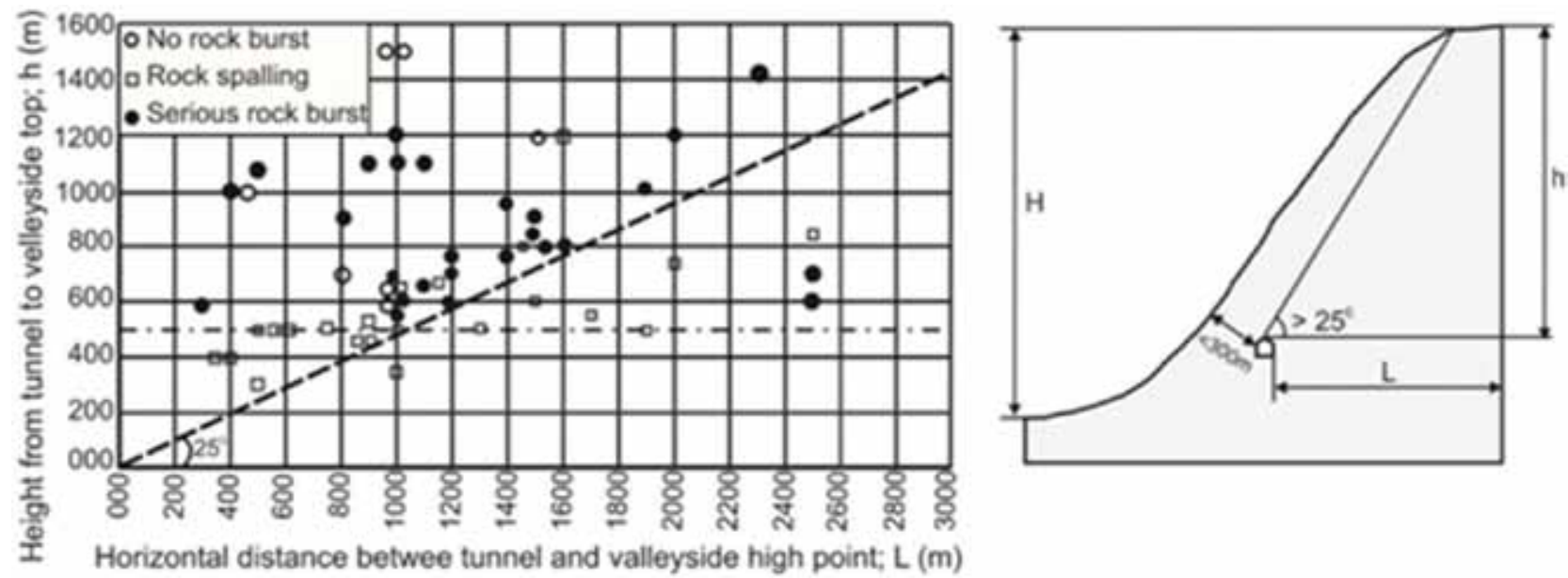

Figure 1. Tunnels having no rock burst, rock spalling and severe rock burst plotted against height from tunnel to top of valley-side slope; i.e. plateau,(left) and horizontal distance between tunnel and valley-side top (right) (Panthi, 2017). The figure is developed based on Olsen (1965).

Figure 1-left above shows tunnels with no rock burst activity, medium rock burst (spalling) condition and high rock burst activity in relation with vertical height between the tunnel and top of valley-side slope (the plateau) and horizontal distance between tunnel and the top of valleyside slope. As one can see in the Figure 1, most of the tunnels that had vertical height (h) between tunnel and plateau less than 500 meters and angle between tunnel location and plateau less than 25 degrees mostly did not experienced any rock burst or rock spalling activities. However, those tunnels that had exceeded this threshold mostly had stability problems associated with rock burst or rock spalling.

According to Panthi (2017), this rule of thumb is useful tool that can be used to start with the first check on whether there is a potential rock spalling/ rock burst activity in tunnels under consideration or not. Nevertheless, one should note here that this method gives indicative results or potential rock spalling/ rock burst activity to those tunnels aligned parallel with the valley side slope with a location within $500 \mathrm{~m}$ distance from the valley side slope topography.

\section{Stress Problem Classification}

Barton et al (1974) of the Norwegian Geotechnical Institute (NGI) proposed the Q-system of rock mass classification. This system is based on a numerical assessment of six different input parameters such as; Rock Quality Designation (RQD), Joint set number (Jn), Joint roughness number (Jr), Joint alteration number (Ja), Joint water reduction factor $(\mathrm{Jw})$, and Stress Reduction Factor (SRF).

The numerical estimation of each of these six input parameters of Q-system can be found in many literatures such as Grimstad and Barton (1993), Barton (2002) and others. The parameter SRF of Q-system is associated to stress induced instability and the part of the SRF table classifies rock spalling/ rock burst potential in a tunnel built in hard rock conditions. The reworked version of the table is presented in the Table 1.

\begin{tabular}{|c|c|c|c|}
\hline $\begin{array}{c}\text { Stress } \\
\text { Class }\end{array}$ & $\begin{array}{l}\text { Description } \\
\text { of potential } \\
\text { stress } \\
\text { induced } \\
\text { instability }\end{array}$ & $\begin{array}{c}\text { Ratio - intact } \\
\text { rock strength } \\
\text { and Major } \\
\text { principle } \\
\text { stress } \\
\left(\sigma_{\mathrm{ci}} / \sigma_{1}\right)\end{array}$ & $\begin{array}{c}\text { Ratio } \\
\text { between } \\
\text { maximum } \\
\text { tangential } \\
\text { stress and } \\
\text { intact rock } \\
\text { strength } \\
\left(\sigma_{\theta-m g x} /\right. \\
\left.\sigma_{\text {ci }}\right)\end{array}$ \\
\hline SC 1 & $\begin{array}{c}\text { Low stress, } \\
\text { near surface, } \\
\text { open joints }\end{array}$ & $>200$ & $<0.01$ \\
\hline SC 2 & $\begin{array}{c}\text { Medium stress, } \\
\text { favorable } \\
\text { stress } \\
\text { conditions } \\
\end{array}$ & $200-10$ & $0.01-0.3$ \\
\hline SC 3 & $\begin{array}{l}\text { High stress, } \\
\text { very tight } \\
\text { structure, } \\
\text { usually } \\
\text { favorable to } \\
\text { blasting except } \\
\text { for wall }\end{array}$ & $10-5$ & $0.3-0.4$ \\
\hline SC 4 & $\begin{array}{c}\text { Moderate } \\
\text { spalling after > } \\
\text { I hour }\end{array}$ & $5-3$ & $0.5-0.65$ \\
\hline SC 5 & $\begin{array}{l}\text { Spalling and } \\
\text { rock burst after } \\
\text { few minutes }\end{array}$ & $3-2$ & $0.65-1$ \\
\hline SC 6 & $\begin{array}{l}\text { Heavy rock } \\
\text { burst and } \\
\text { immediate } \\
\text { strain failure }\end{array}$ & $<2$ & $>1$ \\
\hline
\end{tabular}

Table 1. Stress problems class in competent rock mass based on Q-system (Panthi, 2017).

As indicated in Table 1, the stress problems classification method mainly considers three input variables consisting intact rock strength ( $\sigma c i)$, maximum principle stress $(\sigma 1)$ and maximum tangential stress ( $\sigma \theta$-max). To use this method for the assessment one should have laboratory tested intact rock strength and knowledge about the in-situ stress condition of the area of concern. 


\section{Uniaxial Compressive and Tensile Strength Approach}

It is quite logical to assume that there is an influence of tensile strength on the stress-induced instability in tunnels since higher the tensile strength of the rock material more homogeneous and brittle properties it has. In this respect, Diederichs (2007) proposed qualitative approach for assessing spalling/ rock burst failure, which is directly linked with Uniaxial Compressive Strength (UCS) and Tensile strength (T) of the intact rock. This method assumes that the Crack Initiation (CI) in the rock mass occurs due to internal heterogeneities and strain an-isotropy in the hard, strong and brittle rock mass under compression and the Crack Initiation (CI) is strongly influenced by the internal tensile strength as indicted in Figure 2.

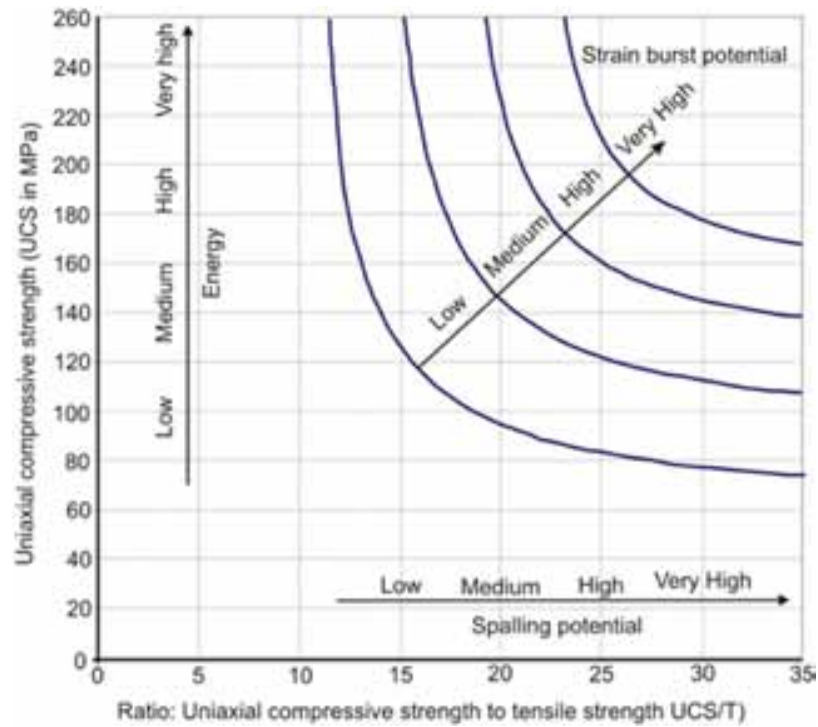

Figure 2. Classification on the potential rock spalling/rock burst based on compressive and tensile strength of the rocks (Panthi, 2017) (Re-produced from Diederichs, 2007).

According to this method of assessment once the rock mass reaches to the spalling condition there develops extension fractures under compressive loading caused by the re-distributed in-situ stresses in the rock mass on the periphery of a tunnel or a cavern. The rock burst event on the other hand represents a violent rupture in the rock mass along the periphery of the tunnel contour under mobilized high stress situation.

It is therefore important to note that in spalling rock mass the extension fracture may develop before the actual rock burst by forming parallel and thin slabs in the tunnel periphery (Panthi, 2017). As per Figure 2, higher the Uniaxial Compressive Strength (UCS) of the rock material and higher the ratio between UCS and Tensile strength ( $\mathrm{T})$, more violent and extensive will be the damage potential in the tunnel wall. The major weakness of this method is that it gives no consideration on the insitu stress condition of the rock mass. Therefore, while carrying out assessment one should also judge on the prevailing in-situ stress condition of the rock-mass and take the assessment as indicative.

\section{Maximum Tangential Stress and Rock Spalling Strength}

The three approaches discussed above provide qualitative assessment of the rock burst and therefore provide no clear picture on the severity of the rock burst (depth-impact) into the rock mass behind the tunnel wall. On the other hand, knowledge on depth-impact as indicated in Figure 3 is crucial in order to build a strategy on the application of rock support (Panthi, 2012). This is particularly important while deciding the length and type of rock anchors and other support means such as mesh, rock straps and steel fiber reinforcement of the tunnel wall so that needed safety and long-term stability of the tunnel is well taken care off.

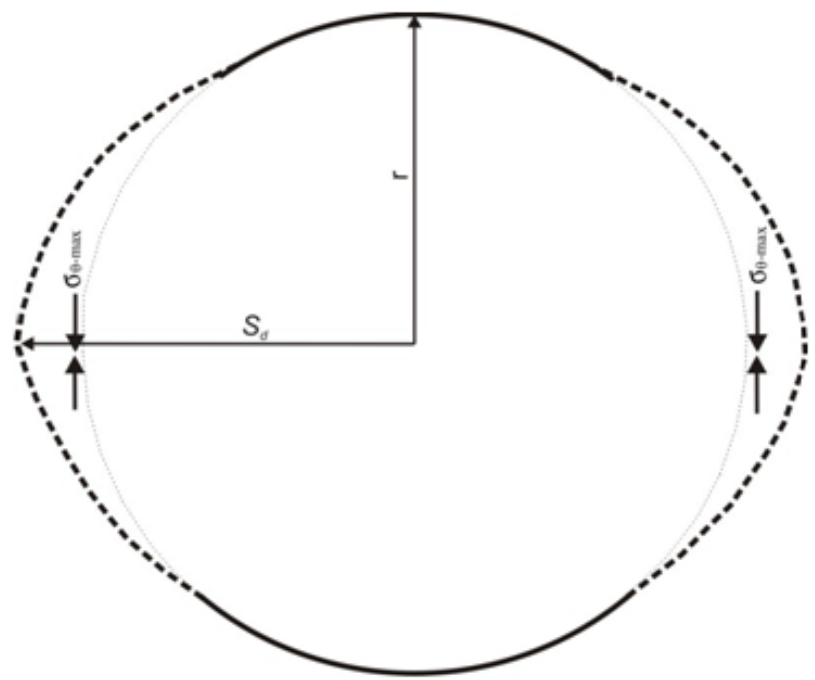

Figure 3. A circular tunnel (TBM tunnel) showing potential damage in the tunnel wall due to accumulated major vertical tangential compressional stress due to stress an-isotropy (Panthi, 2017).

The methodology proposed by Martin and Christiansson (2009) as described by Equation 1 offers a possibility to assess the extent of rock spalling/ rock burst depth-impact in the tunnel wall expressed by $S_{d}$.

$S_{d} \approx r \times\left[0.5 \times \frac{\sigma_{\theta-\max }}{\sigma_{s m}}-0.52\right]$

Where, $S_{d}$ is the distance from tunnel center to the point up to where rock spalling/ rock burst failure may extent into the tunnel wall; $r$ is tunnel radius; $\sigma_{\theta-\max }$ is the maximum tangential compressional stress and $\sigma_{\text {sm }}$ is rock mass spalling strength.

Martin and Christiansson (2009) suggest that the magnitude of in-situ spalling strength for glacially eroded massive Scandinavian Crystalline rocks lies between 55\% 
and $65 \%$ of the intact rock strength while the laboratory tested Crack Initiation (CI) strength may be between 40 and $50 \%$ of the intact rock strength ( $\sigma c i)$. Comparison of the CI values measured in laboratory uniaxial tests and the rock mass spalling strength by Martin et al (1999) suggests that the crack initiation provides the lower bound limit for the rock spalling strength. With this understanding, one can assume that the rock mass spalling strength of massive and brittle rock is likely to be below 0.5 times the mean Uniaxial Compressive Strength (UCS).

\section{Discussions on the Limitations and Applicability}

The four methods presented above are unique and are different in the way the rock spalling/ rock burst phenomenon are assessed in a tunnel passing through strong and brittle rock mass. The Norwegian Rule of Thumb gives a qualitative assessment on where it is safe to place a tunnel that passes through the steep slope topography that extends from the valley bottom to the top of the hillside slope. The Stress Problem Classification Approach provides qualitative assessment based on either ratio between intact rock strength and major principle stress or ratio between maximum tangential compressional strength and intact rock strength. Similarly, Uniaxial Compressive and Tensile Strength Approach gives qualitative assessment based on the intact rock strength and ratio between intact rock strength and tensile strength of the rock material. Similarity between the later two approaches is that both methods assess the extent of severity giving "severity class". The fourth one, the Maximum Tangential Stress and Rock Spalling Strength on the other hand provides an opportunity to assess the extent of rock spalling/ rock burst depth-impact, which is fruitful information in many occasions since such information is valuable in the rock support design, particularly in the estimation of length of rock anchors.

It is important to discuss here that the rock spalling/ rock burst assessment using Stress Problem Classification and Maximum Tangential Stress and Rock Spalling Strength Approaches require knowledge about the in-situ stress condition in the vicinity where planned tunnel will be located. In addition, one should have information on the intact rock strength and method to calculate maximum tangential compressional stress $\left(\sigma_{\theta-\max }\right)$, which can be estimated using Kirsch's equation defined by maximum and minimum principle stresses expressed by Equation 2.

$$
\sigma_{\theta-\max }=3 \sigma_{1}-\sigma_{3}
$$

On the other hand, Panthi (2012) recommends that the rock mass spalling strength $\left(\sigma_{\mathrm{sm}}\right)$ can be replaced with rock mass strength $\left(\sigma_{\mathrm{cm}}\right)$ to calculate the rock spalling/ rock burst depth-impact. For the rock mass influenced by schistosity, rock mass strength $\left(\sigma_{\mathrm{cm}}\right)$ can be estimated using equitation suggested by Panthi (2006), which is expressed by Equation 3. For homogeneous, massive and brittle rocks, one can use Equation 4 (Panthi, 2017) to estimate the rock mass strength $\left(\sigma_{\mathrm{cm}}\right)$.

$$
\begin{gathered}
\sigma_{c m}=\frac{\sigma_{c i}{ }^{15}}{60} \\
\sigma_{c m}=\frac{\sigma_{c e}{ }^{16}}{60}
\end{gathered}
$$

Where, $\sigma_{\mathrm{sm}}=\sigma_{\mathrm{cm}}$ is the rock mass spalling strength or rock mass strength and $\sigma_{\mathrm{ci}}$ is the laboratory tested intact rock strength.

Equation 3 should only be used for the rock mass influenced by schistocity. The major type of stressinduced instability in this case is related mainly to the phenomenon such as rock spalling, rock buckling and plastic deformation. The rock mass strength (rockmass spalling strength) for rocks with high degree of schistocityisin general below 0.3 times the intact rock strength. Equation 4 is appropriate to use for massive and brittle rock mass with homogeneity and high intact rock strength. The experience has shown that crack initiation develops at around 0.5 to 0.6 of its maximum USC in case of very fine grained, homogeneous and very strong to extremely strong rocks. On the other hand, in coarse grained to medium grained, homogeneous and strong to very strong rocks, the crack initiation starts developing once the specimen exceeds the threshold of approximately 0.3 of the USC.

\section{Conclusion}

Assessment on the extent of rock spalling/ rock burst in tunnels passing through massive and brittle rocks is a challenging task in rock engineering. Different assessment methods have been applied worldwide and four of the most common methods have been discussed in this manuscript. All four methods have strength and weaknesses and should be used carefully with good knowledge on the rock mass. The first three methods mainly give qualitative assessment on the rock burst extent. The fourth one can be used to assess the rock burst extent in a quantitative way. However, before doing any assessment on the rock burst potential, the user must have knowledge about the topographic, geological, in-situ stress, intact rock strength and tensile strength characteristics of the rock. The combination of the method proposed by Martin and Christiansson (2009) in combination with Equation 3 and Equation 4 give valuable input on the extent of depth-impact, which many rock engineers wish to have while designing the underground structure. In rock engineering, the issue of subjectivity is always there and one should always be careful while using any prediction methods proposed. 
Dr. Krishna Kanta Panthi is an Associate Professor in Geological Engineering at the Department of Geology and Mineral Resources Engineering, Norwegian University of Science and Technology (NTNU), Norway, since 2008. He holds PhD degree in Rock Engineering, MSc in Hydropower Development and MSc in Tunneling. He is the author of many scientific papers published in very renowned journals internationally. He has more than 20 years of experience in research, design and construction supervision of tunneling, hydropower and slope stability projects.

Corresponding E-mail: krishna.panthi@ntnu.no

\section{References}

Barton N. 2002. Some new Q-value correlation to assist in site characterization and tunnel design. International Journal of Rock Mechanics and Mining Sciences, vol. 39, pp. 185-216.

Barton N., Line R. and Lunde J. 1974. Engineering classification of rock masses for the design of tunnel support. Rock Mechanics, vol. 6, pp. 189-236.

Diederichs, M. S. 2007. Damage and spalling prediction criteria for deep tunneling. Canadian Geotechnical Journal, vol. 44 (9), pp. 1082-1116.

Diederichs, M. S. 2014. When does brittle failure become violent? Spalling and rock burst characterization for deep tunneling projects. Proceedings: World Tunneling Conference 2014, Foz do Iguacu, Brazil.
Grimstad E. and Barton N. 1993. Updating the Q-system for NMT. Proceeding of the International Symposium on sprayed concrete - modern use of wet mix sprayed concrete for underground support, Fagernes. Norwegian Concrete Association, Oslo, Norway.

Martin C. D., Kaiser P. K., McCreath D. R. 1999. HoekBrown parameters for predicting the depth of brittle failure around tunnels. Canadian Geotechnical Journal, vol. 36 (1), pp. 136-151.

Martin C. D. and Christiansson R. 2009. Estimating the potential for spalling around a deep nuclear waste repository in crystalline rock. International Journal of Rock Mechanics and Mining Sciences, vol. 46, pp. 219-228.

Olsen, S. R. 1965. Stabiliteten i tunneler i dalsider (The stability in tunnels in valley-side slopes). IVA rapport 142, pp. 77-83.

Panthi, K. K. 2006. Analysis of engineering geological uncertainties related to tunneling in Himalayan rock mass conditions. Doctoral theses 2006: 41. ISSN 1503-8181. Norwegian University of Science and Technology, Trondheim, Norway.

Panthi, K. K. 2012. Evaluation on rock bursting phenomena in a tunnel of the Himalaya. Bulletin of Engineering Geology and Environments, vol. 71 (4), pp. 761-769.

Panthi, K. K. 2017. Rock burst prediction methods and their applicability. Chapter 11.2 of the book to be published in 2018 with a title "Rock Burst Mechanism, Monitoring, Warning and Mitigation" edited by Xia-Ting Feng. Elsevier / ButterworthHeinemann. 572p. 